\title{
Para cada universo colecionista, suas fontes: dinâmicas informacionais nas tramas de Clifford Janeway
}

\author{
Kelly Castelo Branco da Silva Melo \\ Doutoranda; Universidade Federal do Estado do Rio de Janeiro, Rio de Janeiro, RJ, Brasil; \\ kelly_castelo@hotmail.com \\ Leila Beatriz Ribeiro \\ Doutora; Universidade Federal do Estado do Rio de Janeiro, Rio de Janeiro, RJ, Brasil; \\ leilabribeiro@unirio.br
}

\begin{abstract}
Resumo: O artigo parte do pressuposto que a literatura policial, como modo de registro e expressão de experiências ficcionais, ela mesma também considerada, nos estudos das áreas de Biblioteconomia e Ciência da Informação, uma fonte de informação, constitui-se de uma abordagem que torna possível a análise/interpretação e representação de quadros de referências sócio-históricas e, mais especificamente, de determinadas práticas colecionistas. Como desdobramento de estudos sobre bibliofilia em Memória Social, o artigo toma como campo empírico cinco romances policiais escritos pelo norte-americano John Dunning. Por meio da leitura analítica desses livros, propõe teórica e metodologicamente identificar, recortar e descrever as fontes de informação julgadas relevantes para as dinâmicas das tramas, visando elucidar o que é possível depreender do universo bibliófilo, e o que, nesse universo ficcional, constitui e representa práticas informacionais utilizadas por/em um universo colecionista não ficcional.
\end{abstract}

Palavras-chave: Fonte de Informação. Bibliofilia. Romance policial. Memória.

\section{Introdução}

É intrínseco ao trabalho do cientista não apenas o fazer científico, mas também o refletir a respeito deste. Tal reflexão aprimora metodológica e informacionalmente suas práticas e produções, dando corpo e forma a procedimentos que, a princípio, podem ocorrer de maneira indutiva ou intuitiva. Uma vez que conhecimento científico faz-se em conjunto, e que cada trabalho compõe uma parte desse todo chamado ciência, cujo objetivo primeiro é suprir a necessidade informacional de outros - ou seja, a ciência é feita para que outros possam servir-se dela -, faz-se necessário pensar não somente no produzir em si, mas também no como. Sendo assim, a preocupação com métodos, legibilidade e 
acessibilidade é prerrogativa da produção científica (MEADOWS, 1999; LE COADIC, 1996); e uma questão importante nesse processo são as fontes (MEADOWS, 1999; LE COADIC, 1996; MUELLER, 2007). Para que um texto, por exemplo, seja considerado científico, ele deve atender critérios que lhe confiram tal legitimidade, e as fontes de informação são elementos fundamentais de legitimação. É necessário que lancemos mão daquilo que foi desenvolvido pela comunidade científica antes de nós, para que o que produzamos obtenha corpo e credibilidade. Conhecimento científico, porém, não se faz única e exclusivamente do material ciência, mas sim do encontro desse com a informação não científica ${ }^{1}$, que é um elemento importante de sua construção. Em consonância com esse raciocínio, nosso pensamento constitui-se e apresenta-se por meio do entrelaçamento do acadêmico - teoria da coleção/colecionismo e estudos do campo da Memória Social, principalmente e do não acadêmico - do plano literário, mais especificamente, ficção policial, em espelhamento com narrativas autobiográficas. Enquanto o primeiro vem conferir a sustentação necessária para a elaboração de um trabalho que toma como campo o segundo; este, por sua vez, oferece outras possibilidades de formas de olhar para seu objeto.

Sendo assim, o artigo é um desdobramento de uma dissertação de mestrado, defendida em 2015 (MELO, 2015), inserida em um projeto de pesquisa que entende a coleção como narrativa e espaço de construção de memórias. Narrativa porque, resgatando a relação entre colecionar e narrar (MARSHALL, 2005), propomos que colecionar é narrar com objetos e que as coleções têm algo a nos dizer. E espaço de construção de memórias porque elas “[...] trazem em si valores atribuídos por seus colecionadores [...]” que "[...] podem ser estendidos e atrelados às construções coletivas retomando a lembranças de todo um grupo social, e refletindo os valores das sociedades do período [...]" (RIBEIRO, 2010, p. 6-7), possibilitando, por meio de seus elementos, a construção, preservação e circulação de informação (e, por meio da informação, a memória) e o comunicar de algo sobre os colecionadores, funcionando como meio pelo qual o colecionador se transmite adiante. 
A dissertação, que teve como tema a bibliofilia (colecionismo de livros), desenvolveu-se a partir da série policial escrita pelo norte-americano John Dunning - composta por cinco títulos: Edições perigosas (2007), Impressões e provas (1996), A promessa do livreiro (2006), Assinaturas e assassinatos (2008) e $O$ último caso da colecionadora de livros (2009) -, tomando-a como uma coleção: a coleção do bibliófilo livreiro John Dunning que representa sua vivência/experiência de bibliofilia, utilizando como recurso a ficção policial. Aqui, prosseguimos com a exploração dessa coleção - que é nosso campo empírico - escolhendo como corte temático alguns dos elementos que a compõem: as fontes de informação.

Entende-se que fontes informam para além do seu conteúdo. O fato de determinado grupo escolher um tipo específico de fonte e não outro evidencia suas práticas, seus costumes, as circunstâncias sócio-históricas e como as dinâmicas informacionais entre seus membros se dão. As próprias fontes per se são vestígios da memória das sociedades que as geraram e utilizaram e apontam para os contextos e demandas dos quais emergem. Tais características potencializam-se, teoricamente, se elas - as fontes - também são tomadas como objetos de coleção.

As ferramentas metodológicas e os direcionamentos para a análise das obras são o resultado de nossas leituras no âmbito da Memória Social, da Biblioteconomia e Ciência da Informação e da Bibliofilia/Colecionismo. Uma vez tendo-as realizado (e, claro, revisitando-as sempre), ocupamo-nos da leitura, releitura e observação analítica dos romances, realizando marcações textuais de todos os trechos que ilustrassem categorias, padrões de comportamento e/ou padrões de fala que encontrassem ecos/espelhamentos nos discursos bibliófilos (textos sobre bibliofilia escritos por bibliófilos, normalmente de cunho autobiográfico) e/ou na esfera teórica, tendo por objetivo encontrar/observar a teoria nas narrativas - sendo essas entendidas como representações da prática colecionista e da figura do colecionador feita pelos colecionadores para (futuros) colecionadores - e vice-versa. Para esse trabalho, analisamos esse material sob a perspectiva das fontes informacionais. Traçamos a rede informacional nele apresentada e identificamos, recortamos e descrevemos as fontes fundamentais 
envolvidas em sua dinâmica, a fim de observarmos o que é possível compreender do universo das práticas bibliófilas e seus quadros de referência, tanto no tocante à realidade social, quanto às representações literárias - sendo estas superfícies refletoras da primeira, elementos constitutivos e normativos do imaginário social e de suas formas de ser representado (CRIPPA, 2014) - a partir das fontes nele em uso e de suas características.

\section{Ficção como fonte: literatura policial, memória, informação}

A escrita, como tecnologia de mídia, ampliou o espectro espaço-temporal das formas de compartilhamento de experiências. Em todas as suas manifestações e junto a outros meios, operantes em diversos sistemas simbólicos, ela ajuda a constituir a memória cultural e coletiva de uma sociedade. Como meios comunicacionais das recordações/lembranças, as formas de escrita ficcional caracterizam-se pelo poder de influenciar e moldar tanto a imaginação coletiva de passado/presente/futuro, quanto nossa ideia de realidade (ERLL, 2010).

A literatura, como campo de manifestações artísticas, compõe um conjunto vasto de transfigurações do real - "realidade recriada através do espírito do artista" (COUTINHO, 1978, p. 9). Como a realidade está em constante transformação, na literatura, observamos essas mudanças serem retransmitidas "através da língua para as formas, que são os gêneros" (COUTINHO, 1978, p. 10). Os gêneros são tipos relativamente estáveis de enunciado, criados por demandas particulares de um determinado campo comunicacional (BAKHTIN, 2011). Sendo assim, são modos específicos de usos da linguagem que não ocorrem de maneira indiscriminada, mas sim segundo normas sociais discursivas próprias de cada circunstância/campo, condizentes com o contexto, no qual os atos de fala acontecem (BAKHTIN, 2011). Ao entendermos que os "[...] gêneros discursivos são práticas sóciohistóricas [...]" (MARCUSCHI, 2002, p. [19]), isto é, que são "enunciados sócio-historicamente situados" (COSTA; ORRICO, 2009, p. [2]), podemos observar que neles encontramos evidenciados "os aspectos constitutivos da sociedade a que pertencem" (TODOROV, 1980, p. 50). Devemos encará-los, portanto, como espelhos a refletir indivíduo e sociedade, mas não um que 
devolve tudo sem ser nada, e sim um que devolve tudo inclusive a si mesmo: um espelho que é superfície refletora, ao mesmo tempo em que é reflexo.

O romance policial é um gênero literário caracterizado pela presença do crime e da investigação. Não parece haver consenso quanto aos seus precursores, entretanto, há unanimidade no reconhecimento de que esse gênero começa de fato com a obra Os assassinatos da Rua Morgue ${ }^{2}$ do escritor americano Edgar Allan Poe, publicado em 1841, no periódico Graham's Magazine (DIAS, 1998; FREITAS, 2007). Alguns dos elementos da realidade/tempo, no qual o romance policial consolida-se e que possibilitam sua emergência são: a influência do positivismo, a disseminação da imprensa, o crescimento do público consumidor de jornais, o surgimento da figura do policial/detetive e o processo de urbanização e crescimento das cidades ambientes propícios às atividades criminosas -, vinculado à industrialização (DIAS, 1998; FREITAS, 2007). O foco principal da narrativa policial, que se pretende objetiva e o mais verossímil possível, é o processo de resolução do mistério/crime, sendo esse o enigma que dá a partida no desenrolar dos acontecimentos. Há, portanto, certa "ênfase positivista no raciocínio e na lógica" (FREITAS, 2007, p. 2); lógica, aliás, que é um dos elementos preponderantes diferenciando o romance policial dos demais tipos (DIAS, 1998). "A familiaridade crescente com o repertório científico e o tipo de raciocínio que este demandava foram decisivos para os desdobramentos desse [...] gênero." (ALMEIDA, 2012, p. 107), que ganha força e toma forma com a presença do imaginário científico (ALMEIDA, 2012).

Afirmamos acima que nos gêneros encontramos refletidas as mudanças que transcorrem na vida social (BAKHTIN, 2011). No caso da literatura policial, dentre as transformações sociais refletidas por esse gênero - e dele constituintes - encontra-se, fundamentalmente, a tomada da ciência como tema central do cenário cultural (ALMEIDA, 2012).

Os procedimentos investigativos que constituíram o coração de diversas narrativas policiais [...] emulavam os procedimentos científicos [...] e contribuíram, a seu modo, para ajudar a popularizar certa ideia de ciência diante do grande público (ALMEIDA, 2012, p. 116). 
A discussão dos diversos gêneros literários e, especificamente, sobre literatura policial, nas áreas de Biblioteconomia e Ciência da Informação, já tem merecido algumas reflexões interessantes, ora posicionando os gêneros como objeto de práticas profissionais, ora investigando como as fontes podem servir para representarmos e entendermos o universo de leitores/usuários e seus quadros de referência acerca tanto da realidade social, quanto das construções dos imaginários (individuais e coletivos) (DIAS, 1998; ALMEIDA, 2012). Metodologicamente, Howard Becker (2009) reforça nossa forma de investigar empiricamente tanto a literatura como fonte, quanto as fontes utilizadas pelos personagens literários, que nos ajudam a refletir sobre "as diferentes maneiras de representar o social"3. Almeida (2012, p. 106-107), discorrendo sobre mudanças de "expectativas dos [horizontes] dos leitores" do século XIX, argumenta que a literatura policial (assim como a ficção científica) contribuiu fortemente para o aumento da circulação da informação sobre o conhecimento científico e, notadamente, para o avanço da divulgação/popularização da ciência ${ }^{4}$. Observamos ainda que, na atualidade, o poder de interesse do público/espectador por séries, filmes, romances, etc., e pelo uso de 'ferramentas' (fontes) tecnológicas e informacionais que auxiliam personagens ficcionais (e pelos profissionais que lidam efetivamente com os processos de coleta, identificação, resolução de crimes, etc. e de outras práticas sociais) permanece ${ }^{5}$. Não é à toa que Almeida (2012), ao concluir seus argumentos, reforça tanto a complexidade do "ato de informar-se" nas tramas policiais, como também “[...] a rica relação que se estabelece entre as informações, os sistemas de conhecimentos e os esquemas socioculturais de interpretação que dão, à informação, seu status e seu valor.” (ALMEIDA, 2012, p. 115).

\section{Colecionismo de/nos livros: bibliofilia}

Bibliofilia é uma palavra composta pelos termos gregos $\beta \imath \beta \lambda i o v$ (transliteração para o latim biblion) - livro - e $\varphi \imath \lambda i \alpha$ (transliteração para o latim philia) - amor - que etimologicamente significa "amor aos livros" e que nomeia a prática do colecionar desses objetos ${ }^{6}$. Em sua simplicidade, ela já apresenta alguns de nossos pressupostos: a de que esta é uma jornada de afetos - e, aqui, ressaltamos 
a concepção de que o afeto pode ser entendido como a primeira etapa do processo de produção de memória (GONDAR, 2011) - e, acima de tudo, uma jornada de coleção - a "tentativa de dar sentido e direção ao que nos surpreendeu" (GONDAR, 2011, p. 25).

O filósofo e historiador polonês Krzysztof Pomian afirma que se pode "[...] constatar, sem risco de errar, que qualquer outro objeto natural de que os homens conhecem a existência e qualquer artefato, por mais fantasioso que seja, figura em alguma parte num museu ou numa coleção particular." (POMIAN, 1984, p. 51). Segundo Baudrillard (2012, p. 95), “[...] a fase ativa de colecionamento parece situar-se entre os sete e doze anos de idade [...]" e por meio dela se manifestam as primeiras tentativas de domínio, arranjo, classificação e manipulação do mundo exterior. Essa noção também está presente em Benjamin (1987), quando ele enxerga na coleção infantil o impulso de ir à captura do mundo e uma forma de apropriação, exploração e compreensão do exterior.

Nos estudos colecionistas, parece haver consenso de que existe uma profunda relação "linear e orgânica", não apenas no tocante à prática, mas também em termos de mentalidade, entre a "instituição colecionista contemporânea $^{8 "}$ e a "acumulação pré-histórica" (PEARCE, 2013, p. 30, tradução nossa), podendo a primeira ser entendida como "reverberação cultural" (MARSHALL, 2005, p. 15) da segunda: um reflexo do "imenso lastro de experiências e memórias acumulado por nossa espécie" (MARSHALL, 2005, p. 22). Seja se considerarmos o surgimento de suas primeiras formas nos mobiliários funerários do Neolítico (POMIAN, 1984), ou nos templos gregos da Antiguidade Clássica (PEARCE, 2013), é inegável que as coleções acompanham o homem - "termo que se aplica aqui a todos os representantes do gênero Homo", desde suas origens, produtores de coisas (POMIAN, 1984, p. 70) - por um período expressivo. Sua "relevância trans-histórica" faz com que sua prática manifeste-se de:

[...] diferentes formas em cada momento histórico, compondo um complexo sistema de funções e finalidades, com implicações cognitivas e culturais que jamais deixaram de acrescentar qualidades 
à espécie, em seu desenvolvimento cultural (MARSHALL, 2005, p. 14).

Ou melhor, de acrescentar qualidades e ter qualidades acrescidas, de causar transformações e serem transformadas, em um fluxo bidirecional de afetos (no sentido de afetar, ter efeito sobre), no qual se dá a relação homemobjeto e, em maior grau, homem-coleção. O aparecimento dos primeiros semióforos (que data do Paleolítico superior) marca uma alteração fundamental na vida humana e, segundo Pomian (1984), talvez a mais importante desde o controle do fogo. O surgimento desse tipo especial de objeto, liberto "da servidão de [ser útil]” (BENJAMIN, 2006, p. 243), ou seja, “[...] que não [tem] utilidade [...] mas que [representa] o invisível [e é dotado] de significado [...]" (POMIAN, 1984, p. 71), inaugura o tempo no qual, não apenas a vida material dos homens passa a extrapolar o visível, mas também essas duas dimensões passam a se interpenetrar. "A recolha e, sobretudo, a produção de objetos que representam o invisível testemunham a emergência da cultura no sentido próprio do termo [...]" (POMIAN, 1984, p. 71) e, por conseguinte, do colecionador como um "agente de cultura" (JANEIRA, 2005, p. 28) e de memória, já que, além daquilo que ele projeta de si através das coleções, seus próprios objetos, em seu estado puro, já são mensagem social (MOLES, 1981) e emitem uma "história objeto-temporal" (OLIVEIRA; SIEGMANN; COELHO, 2005, p. 114).

De acordo com Walter Benjamin (1995, p. 228), “[...] toda paixão confina com um caos, mas a de colecionar, com o das lembranças [...]”, ou seja, cada componente da coleção funciona como um portal para um passado particular, para um conjunto de experiências e recordações, para realidades distantes. O mesmo se lê em Phillipp Blom, quando, ao descrever uma coleção composta por souvenires adquiridos em uma viagem, afirma que aqueles objetos "[...] agora são aquelas férias, representante[s] solitários de dez dias de uma vida diferente, uma breve visita a outro mundo" (BLOM, 2003, p. 194, grifo nosso). Uma descrição similar também se encontra em Benjamin (1995), quando, ao relatar o desencaixotar de sua coleção de livros, retrata o afluir de lembranças e imagens do passado - cidades e lugares por onde esteve, fases de sua vida e experiências de sua infância. Note-se que, ao desempacotar sua 
coleção e trazê-la novamente ao olhar, o autor é transportado de volta para a própria vida, de forma que sua coleção de livros diversos é uma coleção dele mesmo, para quem "[...] a posse [é] a mais íntima relação que se pode ter com as coisas: não que elas estejam vivas dentro dele; é ele [o colecionador] que vive dentro delas [...]" (BENJAMIN, 1995, p. 235).

Diante dessa concepção, olhamos para nosso campo empírico - a série policial do bibliodetetive Clifford Janeway - como a coleção de John Dunning dele mesmo: das experiências vividas, dos lugares visitados, dos livros lidos/comprados/vendidos, das pessoas conhecidas e de fontes utilizadas em sua trajetória como bibliófilo e livreiro. Por meio dela, ele nos dá a ver tanto de si, quanto do universo das práticas bibliófilas.

\section{Narrador-colecionador}

A série policial a que nos referimos tem como personagem principal um detetive bibliófilo que chamamos bibliodetetive. John Dunning, ao discorrer sobre Janeway, afirma que ele é uma mistura de suas próprias atitudes com as atitudes de alguns policiais que ele conheceu durante a época em que trabalhou no Denver Post, cobrindo a sessão policial do jornal (DUNNING, 2000, [2014]).

Assim como Dunning, Janeway mora em Denver (EUA) e é livreiro; ambos têm uma livraria no lado leste da cidade - pelo menos até 1994, quando Dunning fechou sua livraria física para continuar com uma loja online (DUNNNG, 2000, [2014]). Os lugares onde as histórias de Janeway se passam são lugares onde as histórias/experiências de vida de Dunning se passaram: Denver - que aparece, ainda que brevemente, em todos os romances da série -, Charleston - cidade onde Dunning cresceu e que compõe uma parte central em A promessa do livreiro (2006) -, o circuito dos hipódromos e estrebarias em Idaho e na Califórnia - onde Dunning trabalhou para criadores e treinadores de cavalos, assim como Janeway em $O$ último caso da colecionadora de livros (2009) -, o circuito das feiras de livros - que Dunning percorreu como livreiro, e que Janeway também menciona ter feito em Assinaturas e assassinatos (2008). Nesse livro, aliás, um dos personagens (o livreiro e amigo de Janeway, chamado Jim Pepper) é "amigo e companheiro livreiro" ${ }^{10 "}$ de John Dunning 
(DUNNING, 2000, doc. sem paginação, tradução nossa). Esse espelhamento criação/criador confere ao imaginário da série contornos firmemente enraizados no real - além daqueles já trazidos, pelo fato de estarmos tratando de romances policiais, que têm a verossimilhança por característica (ALMEIDA, 2012; DIAS, 1998) -, e traz para o universo da literatura policial certo tom autobiográfico $^{11}$, similar ao que encontramos nos textos de bibliófilos escritos sobre bibliofilia e tidos como guias para a arte de colecionar livros ${ }^{12}$.

\section{Na série, o fora da/de série}

A série de Dunning foi escolhida por trazer dinâmicas e especificidades características da bibliofilia, consonantes com as teorias colecionistas e com os discursos de bibliófilos não ficcionais. Sua narrativa é sequencial e desenrola-se a partir do momento em que Janeway resolve deixar a polícia para trabalhar com livros. No entanto, na medida em que bibliocrimes vão acontecendo, ele se vê obrigado a acionar seus talentos e contatos policiais para solucioná-los.

Após a leitura dos romances, uma primeira articulação com aspectos teóricos já se torna visível: cada um deles aborda um critério colecionista distinto, ou seja, trata de um determinado tipo de livro ou de uma característica de livro específica, que faz a transição da esfera de objeto utilitário para a de objeto colecionável. Embora uma coleção possa ter início com um projeto cumulativo de capital e com um propósito quantitativo, é através do colecionar que o colecionador "não autêntico" dá o "salto qualitativo" (BOCK, 2015) para o território da autenticidade, para o espaço da afetividade. Não é possível precisar até que ponto pessoas começam a colecionar porque são apaixonadas, entusiasmadas por algo, ou até que ponto elas se tornam apaixonadas e entusiasmadas por algo através do colecionar. Não existe um padrão único para esses processos: as motivações são tão plurais quanto os indivíduos, e os métodos são tão variados quanto os objetos no mundo.

Segundo Moles (1981), se uma coleção é um conjunto de objetos, e se é física e humanamente impossível colecionar todos os objetos ou categorias de objetos do mundo, um critério de escolha (filtro, padrão de seleção, redução) rege o processo de formação da coleção, que passa a ser então, para além da 
reunião de objetos, a reunião "de elementos de um conjunto" (MOLES, 1981, p. 141) cuja característica principal - a qualidade que aglutina seus componentes e que os transforma em unidade - é previamente definida, essencialmente subjetiva (muito embora, o aspecto social também exerça influência) e nem sempre clara para o observador externo. Se o reunir indiscriminado da totalidade dos objetos é inviável (e dificilmente poderia ser chamado coleção, uma vez que coleção implica seleção), opta-se pela reunião de um tipo de objeto específico que, por sua vez, determina a qualidade do conjunto: o tipo de coleção. O tipo de objeto colecionado torna-se então o elemento definidor da coleção: coleção de selos, coleção de discos de vinil, coleção de livros, etc. E não só da coleção, como também do tipo de colecionador: colecionador de selos, colecionador de discos de vinil, colecionador de livros: bibliófilo.

Quando o tipo de objeto, a categoria escolhida, é ainda abrangente demais, o colecionador ocupa-se em reunir, então, um conjunto de tipos (MOLES, 1981). Se falarmos de bibliofilia, tratamos de coleções de livros livro, aqui, um tipo de objeto. Uma vez que essa categoria é muito ampla e sua reunião indiscriminada diria respeito à bibliomania (acumulação, aquisição sem critério) e não à bibliofilia, outros filtros se fazem necessários: que tipo de livro? E com quais aspectos? Dinâmica claramente observável nos livros de John Dunning, na qual o tipo de livro não só define a coleção, mas também a trama trazida por cada um dos romances: em Edições perigosas (2007), a trama desenrola-se em torno de primeiras edições; em Impressões e provas (1996) aborda-se a temática das edições produzidas por tipografias específicas; em $A$ promessa do livreiro (2006), a história trata de exemplares das primeiras e raríssimas edições dos livros do autor Richard Burton, enviados e dedicados por este a um amigo; Assinaturas e assassinatos (2008) discorre sobre livros cujo valor é conferido pelas assinaturas que carregam e; $O$ último caso da colecionadora de livros (2009) trata sobre primeiras edições de livros infantis. Note-se que a seleção dos componentes das coleções, das quais tratam os romances, não é orientada por apenas um critério, mas também por uma combinação deles. Quanto mais complexa essa combinação, mais o objeto colecionado aproxima-se do objeto único e da singularidade absoluta. 


\section{Fontes que por si já falam}

Ao analisar os romances, a temporalidade da narrativa também faz um elemento informacional relevante. $\mathrm{O}$ fato de suas tramas estarem circunscritas às décadas de 80 e 90 indicam que elas tratam de uma realidade do universo livresco diferente da atual. As histórias falam de um tempo anterior à consolidação dos novos modos de circulação informacional instaurados pela Revolução da Tecnologia da Informação (CASTELLS, 1999), no qual as trocas informacionais se dão, fundamentalmente, via meios impressos e contato interpessoal - o que também influencia nas fontes em dinâmica e na constituição da rede informacional do grupo.

Dentre todas as fontes de informação que constam da série policial em questão, separamos para análise as que têm alguma importância no fluxo de resolução dos crimes: personagem, diário, fotografia, biografia, bibliografia, carta, coleção e periódico. Vale lembrar que, uma vez que trabalhamos com literatura policial, o fluxo informacional é elemento chave não só para a constituição da narrativa em si como também para a solução do enigma, que é seu objetivo. Se em todo romance policial há um mistério a ser resolvido, o personagem principal - normalmente, o detetive - se faz valer de fontes de informação para desvendá-lo.

Os personagens foram tomados como fontes devido à importância que o contato interpessoal tem nos livros - o que evidencia o contexto sócio-histórico no qual as tramas se inserem. Sem esse contato, o crime se torna insolúvel, e é por meio dele que a grande maioria das trocas informacionais se dá. Para além do contexto policialesco de resolução do mistério, o contato entre pessoas emerge como fundamental para o aprendizado da arte de colecionar, ou seja, para aprender sobre livros e o universo livreiro. Janeway revela que muito do que sabe sobre livros aprendeu com livreiros, seja por meio de conversas, seja vendo-os trabalhar. Ele também sempre recorre a colegas de profissão - da força policial, ou do meio livresco - para tirar dúvidas ou descobrir algo. A assinatura (autógrafo) em um livro que ele compra, em Assinaturas e assassinatos (2008), só se revela uma falsificação porque um de seus amigos livreiros percebe e o alerta para o fato. É por meio da rede dos livreiros que ele tem acesso a uma 
série de informações privilegiadas: a ocorrência de leilões, a existência de coleções à venda, a reputação de outros livreiros e colecionadores. Em Edições perigosas (2007), é possível perceber que é nas livrarias, observando outros bookmen em ação, que os alfarrabistas ${ }^{13}$ aprendem seu ofício: sem material de referência, apenas olhando os livros nas estantes, verificando os preços, entreouvindo conversas. Em suma: o círculo social dos bookmen é essencial tanto para colecionadores quanto para livreiros, noção que é bastante reforçada, por exemplo, no guia para bibliófilos - O bibliófilo aprendiz - de Rubens Borba de Moraes (2005).

As coleções são elementos informacionais centrais nas tramas, seja quando se revelam como conjunto, seja quando Janeway encontra partes delas, soltas, como peças de um quebra-cabeça. Seus "pedaços" representam migalhas de pão a guiar Janeway pelo caminho, reforçando a ideia de que uma coleção bibliófila, ainda que desmembrada, deixa rastros, ou seja, de que suas partes, ainda que separadas, remetem à unidade que um dia formaram e à pessoa que as constituiu. Ao tratarmos da categoria coleção, como fonte de informação, também nos referimos aos livros, já que os relevantes e importantes no contexto da trama são todos objetos de coleção. Eles ocupam um espaço privilegiado na narrativa, desempenhando seu papel de vetores/fontes informacionais, não apenas por meio de seu conteúdo, como também por meio das características de sua materialidade: edição, encadernação, marcas de leitura, dedicatórias, etc. Todos esses elementos são explorados por Janeway como recursos para a resolução dos crimes e também para informar sobre traços específicos do mercado de livros antigos e raros, e sobre as práticas desse tipo de colecionismo. Ao discorrer sobre assinaturas e autores específicos, Janeway ensina aos leitores o que faz um item colecionável ou não (DUNNING, 2008); ao mencionar a presença de frontispício em um exemplar, ele apresenta a existência desse tipo de ilustração e sua relevância para esse universo (DUNNING, 1996); como um guia para colecionadores, ele alerta para a existência de sinais (como erros de impressão) que identificam determinadas edições de forma até mais eficiente do que dados bibliográficos (DUNNING, 2007) e para indícios de fraude ou falsificação (tipo de papel, irregularidade na costura ou no alinhamento das 
páginas), (DUNNING, 1996) que, para leigos, passariam despercebidos. Todos esses aspectos - e inúmeros outros abordados no decorrer das tramas - veiculam um tipo de informação que, muitas vezes, só se faz perceptível para aqueles com conhecimento sobre o assunto, o que, nesse universo, em que se "[...] toma dos burros e vende aos espertos [...]" (DUNNING, 1996, p. 60), é fundamental.

As bibliografias e biografias aparecem como fontes de apoio e referência, tanto para os negociantes como para os compradores/colecionadores de livros. Por meio das bibliografias, Janeway mostra como é possível tomar conhecimento de pormenores de cada edição publicada, reunida pelo bibliógrafo com base em algum critério: um autor em especial, um editor/impressor específico, etc.. Esse conteúdo bibliográfico guia, por exemplo, as escolhas de colecionadores quanto ao que comprar, e as de livreiros quanto ao que vender, servindo como parâmetro para salvaguarda de enganos e de práticas inescrupulosas (DUNNING, 2006). Dunning (1996), por meio de Janeway, apresenta ao leitor as bibliografias como obras de referência, frutos de pesquisas extensas e meticulosas, sinalizando o tipo de informação que é possível extrair delas e em que consiste o trabalho de um bibliógrafo. Nesse universo, biografias - que, segundo as qualidades próprias do gênero histórico-literário, trazem informações a respeito da vida de alguém (VIANNA; MARQUES JÚNIOR, 1998) - são evocadas como auxiliares no conhecimento e localização de exemplares, ou como estratégias para alimentar o interesse por uma determinada pessoa (o que pode guiar uma coleção) ao discorrerem sobre autores ou editores/impressores. Esses aspectos são observáveis, principalmente, nos dois romances que têm bibliografias e biografias como fontes fundamentais: Impressões e provas (1996) e A promessa do livreiro (2006). No primeiro título, a bibliografia de uma tipografia é colocada em par com a biografia dos tipógrafos responsáveis por ela, a fim de guiar tanto os colecionadores dos livros impressos por essa casa impressora, como a jornada de Janeway, na tentativa de encontrar um deles. Quer dizer, Dunning (1996) ilustra como é possível mapear a trajetória de uma obra e localizá-la a partir de informações biográficas e bibliográficas. Os mesmos papéis são atribuídos à bibliografia e à biografia de Richard Francis Burton, no segundo título. Aliás, constituem pontos onde, na 
trama, ficção e não ficção se interpenetram, uma vez que são livros reais publicados, sobre o explorador e o diplomata britânico, utilizadas por Janeway para cumprir com suas funções de bibliodetetive e localizar, não apenas um livro, mas uma coleção deles. E ainda, para decidir que obra de Burton comprar para a sua coleção particular. Tarefa para a qual ele também utiliza a revista $A B$ como recurso.

A categoria "periódico" subdivide-se em dois tipos: revista especializada e jornal. A primeira subcategoria é representada pela revista AB/Bookman's Weekly que é uma publicação do ramo dos livros raros e usados e que é apresentada por Janeway como leitura de lazer e, também, como fonte de informação sobre o mercado livreiro. Ela é outro ponto de convergência ficção/não ficção, embora, atualmente, a revista impressa não exista mais, por conta das mudanças decorrentes da entrada das novas tecnologias nesse universo (DUNNING, 2000). A $A B$, tanto no plano não ficcional quanto na ficção, teve/tem um papel importante na circulação dos livros e da informação sobre eles. Publicando vastas listas de exemplares à venda, anúncios de livros procurados para a compra, além de dados sobre eventos do mercado livreiro, a revista constitui um instrumento importante para as trocas entre livreiros e colecionadores. Ao escrever sobre a revista, Dunning sinaliza que esse tipo de fonte existe e a que tipo de demanda informacional ele atende/corresponde. Jornais, desde sua concepção - que se confunde com a própria história da imprensa -, servem como fonte de informação noticiosa, documento histórico e/ou como fonte de informação para demandas específicas (TEIXEIRA, 1998), e o fazem tanto fora das páginas da série de Janeway, quanto dentro delas. Notícias contribuem para que informações sejam/possam ser apuradas, o que se observa na série, por exemplo, quando, através de jornais, Janeway comprova que os assassinatos em Impressões e provas (1996) têm relação com um livro. Como documento histórico, possibilitam que determinados fatos, locais e lugares possam ser interpretados de forma mais sistemática, como quando, em $A$ promessa do livreiro (2006), Janeway utiliza-se de jornais para checar, por meio da ocorrência ou não de determinados fatos, a credibilidade/veracidade do relato de uma cliente. Em relação a demandas específicas, os jornais suprem 
necessidades acerca do mercado livreiro, informando sobre leilões, pessoas físicas e jurídicas, etc.. Foi na cobertura de imprensa sobre um leilão, onde Janeway comprou um livro raro, que uma cliente encontrou o bibliodetetive e uma nova pista a respeito de um livro que lhe foi roubado (DUNNING, 2006). Foi nos jornais que Janeway descobre a respeito de um bibliófilo e sua coleção de livros (DUNNING, 2006), e que ele faz uma pesquisa preliminar sobre a morte de um colecionador (DUNNING, 2009). Além de fonte de novas informações, a fotografia pode servir como instrumento de reiteração de determinados dados, como documento de prova (promovendo a identificação de um lugar, objeto ou pessoa) ou prestar-se a análises iconográficas e comparativas. Assim como, os periódicos e as fotografias são fontes informacionais bastante exploradas por diversas áreas do conhecimento. A novidade, nos romances de Janeway, é o representar de como essas fontes da vida cotidiana podem suprir demandas informacionais próprias do universo do colecionismo de livros. É por meio de uma foto, por exemplo, que Janeway confirma a passagem/presença de um colecionador em determinada localidade, o que lhe dá pistas para encontrar o paradeiro de sua coleção desaparecida (DUNNING, 2006). É, também, mediante a análise das fotografias de cenas de crimes - assassinatos de bibliófilos - que o bibliodetetive percebe que livros foram retirados de suas estantes (DUNNING, 1996), um indício de um possível retorno destes ao circuito das trocas.

Diários, por se tratarem de formas de "escrita das coisas da gente" (CHASSOT, 2005a, p. 58), são fontes de natureza biográfica que trazem informações das mais diferentes esferas da vida de uma pessoa. Por serem historicamente e culturalmente datados, constituem-se de uma fonte informacional de destaque, principalmente, para aqueles que se dedicam ao gênero biográfico e seus estudos (CHASSOT, 2005a). Essa relação próxima entre diários e biografias, inclusive, pode ser observada nas tramas da série policial e na descrição dos diários como elementos cobiçados e disputados por biógrafos (DUNNING, 1996, 2006). Outro relacionamento próximo, também muito presente, é aquele entre diários e coleção, no qual os primeiros são narrados/representados tanto como objetos de coleção - e objetos de desejo de 
colecionadores -, quanto como uma forma de colecionar ${ }^{14}$ (DUNNING, 1996, 2006, 2009).

As cartas são nosso último tipo de fonte e, bem como os diários, elas aparecem também como objetos de coleção operam como extensões daqueles que as escrevem e como fontes de informação sobre suas vidas e práticas. Como disse Foucault (2012, p. 152, grifo do autor), em suas considerações acerca da correspondência na Antiguidade Clássica: “[...] escrever é [...] 'se mostrar', se expor, fazer aparecer seu próprio rosto perto do outro [...]”. Principalmente, no âmbito da troca de cartas pessoais que é o universo que Dunning explora, em todos os romances. Nele, as cartas são pedaços de si que as pessoas projetam para fora, para o outro, e lê-las é como estar com essas pessoas novamente: dentro da rede interpessoal, trocando informações.

\section{Considerações finais}

Após a leitura dos livros de Janeway, observamos uma rede de trocas informacionais que, assim como a comunidade científica (LE COADIC, 1996; MEADOWS, 1999), faz uso de canais comunicacionais tanto formais - no caso dos livros, das publicações especializadas e das obras de referência -, quanto informais - cartas, diários, fotografias, coleções particulares e relações interpessoais. Ao olhar para esses canais - aqui, fontes informacionais -, percebe-se que há mais neles do que seu conteúdo. Os elementos que os compõem e a forma como se articulam apontam para questões de temporalidade, dinâmicas de valor e aspectos referentes ao contexto social.

Nesse sentido, fontes podem ser vistas como suportes de memória, reflexos das sociedades que as produziram e dos sujeitos que as criaram. Como o espelho de um telescópio, elas compõem a imagem de parte de um universo que pode não mais existir - ou existir apenas através delas.

Tomando como exemplo as dinâmicas e os processos em jogo, na temática das fontes, em nosso campo empírico, percebemos a importância do contato entre pessoas, tanto para a construção do conhecimento sobre livros, como para a sua disseminação. Moraes (2005) afirma que o melhor guia que um colecionador pode ter é um bom livreiro e vice-versa, e essa mesma noção 
também habita os livros de Dunning (1996, 2000, 2006, 2007, 2008, 2009), de Mindlin (1997, 2009), de Frieiro (1999), de Eco (2010), etc. Observando as fontes que Janeway e outros bookmen utilizam, é possível perceber que, no universo bibliófilo retratado na série - espelho/reflexo do universo bibliófilo não ficcional da mesma época -, saber sobre livros não é apenas adquiri-los e tê-los, mas também estudá-los - principalmente, com materiais produzidos por outros que também os adquirem e têm, ou seja, por pares -, transitar por onde eles transitam, conviver com outros que com livros convivem, trocar, caçar, falar de livros, o que remete a um tempo e a uma prática que valorizam a experiência (no contexto benjaminiano), e as fontes que aproximam pessoas e, também, atuam como elementos de identidade/organicidade de grupo.

Quer dizer, aproximaram pessoas e atuaram como elementos identitários, porque tanto Dunning (2000), como Janeway (DUNNING, 2009), como Moraes (2005) e outros bibliófilos apontam para mudanças provocadas no mundo da bibliofilia, pelo advento da internet e das reconfigurações sociais decorrentes da consolidação das novas tecnologias de informação e comunicação. Ao nos debruçamos em obras da literatura policial, para nelas buscar, empiricamente, potenciais suportes de informação e de memória, encontramos, para além destes, elementos teóricos e analíticos para a discussão do mundo da bibliofilia.

\section{Referências}

ALBERTI, Verena. Literatura e autobiografia: a questão do sujeito na narrativa. Estudos Históricos, Rio de Janeiro, v. 4, n. 7, p. 66-81, 1991. Disponível em: <http://bibliotecadigital.fgv.br/ojs/index.php/reh/article/view/2313/1452>. Acesso em: 23 fev. 2014.

ALMEIDA, Marco Antônio de. Literatura, informação, conhecimento e ciência: considerações a partir da literatura policial. In: ALMEIDA, Marco Antônio de. Ciência da Informação e literatura. Campinas: Alínea, 2012. p. 91-118.

ARTIÈRES, Philipe. Arquivar a própria vida. Estudos Históricos, Rio de Janeiro, v. 2, n. 21, p. 9-34, 1998. Disponível em:

<http://bibliotecadigital.fgv.br/ojs/index.php/reh/article/viewArticle/2061>. Acesso em: 7 nov. 2014. 
AULETE, Caldas. iDicionário. [Rio de Janeiro]: Lexicon Editora Digital, [2008]. Disponível em: 〈http://aulete.uol.com.br〉. Acesso em: 10 fev. 2017.

BAKHTIN, Mikhail. Estética da criação verbal. 6. ed. São Paulo: Martins Fontes, 2011.

BAUDRILLARD, Jean. O sistema dos objetos. 5. ed. São Paulo: Perspectiva, 2012.

BECKER, Howard S. Falando da sociedade: ensaios sobre as diferentes maneiras de representar o social. Rio de Janeiro: Jorge Zahar, 2009.

BENJAMIN, Walter. Ampliações. In: BENJAMIN, Walter. Obras escolhidas II: rua de mão única. São Paulo: Brasiliense, 1987. p. 37-40.

BENJAMIN, Walter. Desempacotando minha biblioteca: um discurso sobre o colecionador. In: BENJAMIN, Walter. Obras escolhidas II: rua de mão única. 5. ed. São Paulo: Brasiliense, 1995. p. 227-235.

BENJAMIN, Walter. O colecionador. In: BENJAMIN, Walter. Passagens. Belo Horizonte: Editora da UFMG; São Paulo: Imprensa Oficial do Estado de São Paulo, 2006. p. 237-246.

BLOM, Philipp. Ter e manter: uma história íntima de colecionadores e coleções. Rio de Janeiro: Record, 2003.

BOCK, Wolfgang. Coleção e restos. Rio de Janeiro: PPGMS/UNIRIO, 2015. Notas de aula.

CÂMARA, Bira. Alfarrábios e bibliofilia. Jornal do bibliófilo: literatura e bibliofilia, [S.1.], 26 abr. 2009. Disponível em: 〈http://jornalivros.com.br/>. Acesso em: 10 jul. 2014.

CASTELLS, Manuel. A sociedade em rede. São Paulo: Paz e Terra, 1999.

CHASSOT, Attico. Escrever diários como uma forma de colecionismo.

Episteme, Porto Alegre, n. 20, p. 55-70, jan./jun. 2005a.

CHASSOT, Attico. O amor como catalisador de colecionismo. Episteme, Porto Alegre, n. 20, p. 149-152, jan./jun. 2005b.

COSTA, Robson Santos; ORRICO, Evelyn Goyannes Dill. A construção de sentido na informação das histórias em quadrinhos. DataGramaZero, Rio de Janeiro, v. 10, n. 2, abr. 2009. Disponível em:

<http://www.datagramazero.org.br/abr09/Art_01.htm>. Acesso em: 12 mar. 2014. 
COUTINHO, Afrânio. Notas de teoria literária. 2. ed. Rio de Janeiro:

Civilização Brasileira, 1978.

CRIPPA, Giulia. Poéticas da informação: representações artísticas e literárias de livros, bibliotecas e de seus protagonistas. São Paulo: Todas as Musas, 2014.

DIAS, Eduardo Wense. O romance policial. In: CAMPELLO, Bernadete Santos; CALDEIRA, Paulo da Terra; MACEDO, Vera Amália Amarante (Org.).

Formas e expressões do conhecimento: introdução às fontes de informação. Belo Horizonte: Escola de Biblioteconomia da UFMG, 1998. p. 101-113.

DUNNING, John. A promessa do livreiro. São Paulo: Companhia das Letras, 2006.

DUNNING, John. Assinaturas e assassinatos. São Paulo: Companhia das Letras, 2008.

DUNNING, John. Edições perigosas. 2. ed. São Paulo: Companhia das Letras, 2007.

DUNNING, John. Impressões e provas. São Paulo: Companhia das Letras, 1996.

DUNNING, John. John Dunning's biography. Arvada: Old Algonquin books, [2014]. Disponível em: <http://www.oldalgonquin.com/authorPage.php>. Acesso em: 18 jan. 2015.

DUNNING, John. O último caso da colecionadora de livros. São Paulo: Companhia das Letras, 2009.

DUNNING, John. Then and now. In: DUNNING, John. Booked to die: a mystery introducing Cliff Janeway. New York: Schreibner, 2000.

ECO, Umberto. A memória vegetal: e outros escritos sobre bibliofilia. Rio de Janeiro: Record, 2010.

ERLL, Astrid. Literature, film and mediataly of cultural memory. In: ERLL, Astrid; NÜNNING, Ansgar (Ed.). A companion to cultural memory studies. Berlim: Walter de Gruyter, 2010. p. 289-398.

FOUCAULT, Michel. Ética, sexualidade, política. 3. ed. Rio de Janeiro: Forense Universitária, 2012.

FRIEIRO, Eduardo. Os livros nossos amigos. Belo Horizonte: Itatiaia, 1999.

FREITAS, Adriana. Romance policial: origens e experiências contemporâneas. Revista Contracultura, Niterói, n. 1, dez. 2007. Disponível em: 
<http://www.uff.br/revistacontracultura/Adriana\%20Freitas_artigo_romance_po licial.pdf>. Acesso em: 2 ago. 2013.

GINZBURG, C. Sinais: raízes de um paradigma indiciário. In: GINZBURG, C. Mitos, emblemas, sinais: morfologia e história. 2. ed. São Paulo: Companhia das Letras, 1989. p. 143-179.

GONDAR, Jô. Quatro proposições sobre memória Social. In: DODEBEI, Vera; GONDAR, Jô (Org.). O que é memória social? Rio de Janeiro: Contra Capa, 2011.

JANEIRA, Ana Luísa. A configuração epistemológica do colecionismo moderno (séculos XV-XVIII). Episteme, Porto Alegre, n. 20, p. 25-36, jan./jun. 2005. Disponível em: <http://www.ilea.ufrgs.br/ episteme/portal/pdf/numero20/episteme20_artigo_janeira.pdf>. Acesso em: 1 nov. 2013.

LE COADIC, Yves-François. A ciência da informação. In: LE COADIC, YvesFrançois. A ciência da informação. Brasília: Briquet de Lemos, 1996. cap. 4.

MARCUSCHI, Luiz Antonio. Gêneros textuais: definição e funcionalidade. In: DIONISIO, Angela Paiva; MACHADO, Anna Rachel; BEZERRA, Maria Auxiliadora (Org.). Gêneros textuais e ensino. Rio de Janeiro: Lucerna, 2002.

MARSHALL, Francisco. Epistemologias históricas do colecionismo. Episteme, Porto Alegre, n. 20, p. 13-23, jan./jun. 2005. Disponível em:

<http://www.ilea.ufrgs.br/ episteme/portal/pdf/numero20/episteme20_artigo_marshall.pdf>. Acesso em: 1 out. 2011.

MEADOWS, A. J. Canais de comunicação científica. In: MEADOWS, A. J. A comunicação científica. Brasília: Briquet de Lemos, 1999. Cap. 4.

MELO, Kelly Castelo Branco da Silva. Bibliófilos e bibliodetetives: personagens de patrimônio e memória. 2015. Dissertação (Mestrado em Memória Social) - Universidade Federal do Estado do Rio de Janeiro, Rio de Janeiro, 2015.

MIKHAILOV, A. I.; CHERNIY, A. I.; GILIAREVSKII, R. S. Estruturas e principais propriedades da informação científica. In: GOMES, Hagar Espanha (Org.). Ciência da informação ou informática? Rio de Janeiro: Calunga, 1980. p. 71-90.

MINDLIN, José. No mundo dos livros. Rio de Janeiro: Agir, 2009.

MINDLIN, José. Uma vida entre livros: reencontros com o tempo. São Paulo: EDUSP, 1997. 
MOLES, Abraham A. Teoria dos objetos. Rio de Janeiro: Tempo Brasileiro, 1981.

MORAES, Rubens Borba de. O bibliófilo aprendiz, ou, Prosa de um velho colecionador para ser lida por quem gosta de livros, mas pode também servir de pequeno guia aos que desejam formar uma coleção de obras raras antigas ou modernas. 4. ed. Rio de Janeiro: Casa da Palavra, 2005.

MUELLER, Suzana Pinheiro Machado. A ciência, o sistema de comunicação científica e a literatura científica. In: CAMPELLO, Bernadete Santos;

CENDÓN, Beatriz Valadares; KREMER, Jeannette Marguerite (Org.). Fontes de informação para pesquisadores e profissionais. Belo Horizonte: Editora UFMG, 2007. p. 21-34.

OLIVEIRA, Andréia Machado; SIEGMANN, Christiane; COELHO, Débora. As coleções como duração: o colecionador coleciona quê? Episteme, Porto Alegre, n. 20, p. 111-119, jan./jun. 2005. Disponível em:

<http://www.ilea.ufrgs.br/episteme/portal/pdf/numero20/episteme20_artigo_oliv eira_siegman_coelho.pdf>. Acesso em: 1 out. 2011.

OLIVEIRA, Carmen Irene C. de. O remake: produzir sentidos diferentes a partir do mesmo. Ou como a informação não científica articula a relação cinema/memória/ciência. 2009. 277 f. Tese (Doutorado em Ciência da Informação) - Universidade Federal Fluminense, Rio de Janeiro, 2009.

PEARCE, Susan M. On collecting: an investigation into collecting in the European tradition. New York: Routledge, 2013.

POMIAN, Krzysztof. Colecção. In: ENCICLOPÉDIA Einaudi: MemóriaHistória. Lisboa: Imprensa Nacional: Casa da Moeda, 1984. p. 51-86.

RIBEIRO, Leila Beatriz. Manias, trecos, objetos e coleção: memória, descarte e velhice nas narrativas quadrinísticas de Urbano, o Aposentado. In: ENCONTRO REGIONAL DA ANPUH-RIO, 19., 2010, Rio de Janeiro. Anais... Rio de Janeiro: NUMEN, 2010. Disponível em:

<http://www.memoriasocial.pro.br/linhas/professores_dados.php?id=19>. Acesso em: 6 out. 2011.

TEIXEIRA, Nísio. Jornais: trajetórias e possibilidades. In: CAMPELLO, Bernadete Santos; CALDEIRA, Paulo da Terra; MACEDO, Vera Amália Amarante (Org.). Formas e expressões do conhecimento: introdução às fontes de informação. Belo Horizonte: Escola de Biblioteconomia da UFMG, 1998. p. 287-314.

TODOROV, Tzvetan. A origem dos gêneros. In: TODOROV, Tzvetan. Os gêneros do discurso. São Paulo: Martins Fontes, 1980. 
UTSCH, Ana. O livro como coleção: bibliofilia, edição, encadernação e literatura na França do século XIX. Revista Brasileira de História da Mídia, São Paulo, v. 4, n. 2, p. 59-68, jul./dez. 2015. Disponível em:

<http://www.unicentro.br/rbhm/ed08/dossie/06.pdf>. Acesso em: 22 fev. 2017.

VIANNA, Márcia Milton; MARQUES JÚNIOR, Alaôr Messias. Fontes biográficas. In: CAMPELLO, Bernadete Santos; CALDEIRA, Paulo da Terra; MACEDO, Vera Amália Amarante (Org.). Formas e expressões do conhecimento: introdução às fontes de informação. Belo Horizonte: Escola de Biblioteconomia da UFMG, 1998. p. 287-314.

\title{
For each collecting universe, their sources: informational dynamics in the Clifford Janeway Series
}

\begin{abstract}
This article is based on the premise that police romance, as a means of recording and expressing fictional experiences (considered in Library Science and Information Science studies as a source of information). It is constituted in a way that makes analysis/interpretation and representation of socio-historical references possible, more specifically, about certain collecting practices. As a product of studies on bibliophilia in Social Memory, the article takes as empirical field five police novels written by the American author John Dunning. Through the analytical reading of these books, he proposes, theoretically and methodologically, to identify, outline and describe the sources of information deemed relevant to the dynamics of the plots, in order to elucidate what can be inferred about the bibliophile universe and what, in this fictional universe, constitutes and represents informational practices used by/in a non-fictional collecting universe.
\end{abstract}

Keywords: Information Source. Bibliophilia. Police Romance. Memory.

Recebido em: 01/11/2016

Aceito em: 08/03/2017

${ }^{1}$ A esse respeito ver Mikhailov, Cherniy e Giliarevskii (1980). Para um aprofundamento da discussão sobre informação não-científica ver ainda Oliveira (2009).

${ }^{2}$ Título original The murders in the Rue Morgue, por vezes traduzido como Os Crimes da Rua Morgue. 
${ }^{3}$ Referência ao subtítulo do livro de Becker (2009).

${ }^{4}$ Ver também Oliveira (2009) para aprofundamento dessas questões.

${ }^{5}$ Ver ainda Ginzburg (1989).

${ }^{6}$ Para o aprofundamento e discussão de outros aspectos acerca do tema ver Utsch (2015).

${ }^{7}$ Do original em inglês: linear and organic connection.

${ }^{8}$ Do original em inglês: contemporary institution of collecting.

${ }^{9}$ Do original em inglês: prehistoric hoarding.

${ }^{10}$ Do original em inglês: Jim Pepper, my friend and fellow bookseller.

${ }^{11}$ A noção de autobiografia como instrumento de arquivamento/colecionamento do eu e forma de escrita de si se encontra melhor explorada em Artières (1998), cujos exemplos, inclusive, sinalizam como essas produções também podem ser tomadas como fontes de informação. $\mathrm{O}$ autor também trabalha com correspondências e diários, o que também encontramos em Chassot (2005a), e em Chassot (2005b). Para pensar a autobiografia como reconstituição da experiência vivida numa construção para a leitura ler Alberti (1991).

${ }^{12}$ Livros de bibliófilos, com conteúdo autobiográfico, escritos como "guias" - como o Uma vida entre livros, de José Mindlin (1997), Os livros, nossos amigos, de Eduardo Frieiro (1999), O bibliófilo aprendiz, de Rubens Borba de Moraes (2005), o Memória vegetal, de Umberto Eco (2010) (que, mais do que conteúdo autobiográfico, é uma obra ensaística), entre outros foram trabalhados em conjunto com as teorias colecionistas, estabelecendo paralelos com aquilo que a série de Dunning traz. As falas de Janeway (personagem) muito se assemelham às falas dos bibliófilos não ficcionais. E isto não acontece por acaso. Na realidade, as falas do bibliodetetive são reverberações ficcionais das falas do bibliófilo John Dunning, sendo o primeiro a criação artística que o segundo constrói de si mesmo.

${ }^{13}$ O termo alfarrabista vem de alfarrábio, que por sua vez provém do "[...] antropônimo árabe Al-Farabi, filósofo que viveu em Bagdá no século IX [...]” (CÂMARA, 2009, p. [1]), e significa "livro usado ou velho" (AULETE, [2008]; CÂMARA, 2009). Alfarrabista, portanto, é aquele que lida com alfarrábios, mas o termo, normalmente, é usado para designar aquele que negocia com alfarrábios (AULETE, [2008]; CÂMARA, 2009). Nos livros de Dunning, no entanto, alfarrabista é a palavra escolhida como tradução para bookscout (DUNNING, 2000) o que seria, em uma tradução mais literal, olheiro de livros - um tipo particular de negociante de livros: "um caçador de livros raros" (DUNNING, 2007, p. 25).

${ }^{14}$ Noção que se confirma em Chassot (2005a). 